\title{
ARTICULO CIENTIFICO
}

Aporte científico a:

Ciencias de la Educación (Neuroaprendizaje - Neurolearning)

Título:

EL APRENDIZAJE DE LA LENGUA ESCRITA

Subtítulo:

Etapa entre los 6 y los 12 años, aprendizaje y lectura

Nombre del autor:

Dr. Carlino Iván Morinigo

Director:

Diosnel Centurión, Ph.D

Lugar y Año de publicación:

Asunción, 2016 


\section{RESUMEN}

Dado el carácter más tecnologizado de las actividades que los sujetos deben desempeñar tanto en los puestos de trabajo, con la utilización cada vez más extendida del ordenador, como en el propio hogar, con el uso de aparatos electrodomésticos, cuyo manejo exige la lectura atenta del manual de instrucciones, se constata que el acceso y al lenguaje escrito es necesario en las sociedades occidentales. Probablemente, no es exagerado afirmar que el dominio del lenguaje escrito es un medio indispensable para acceder a la cultura y al conocimiento en general. En realidad, el hecho de poseer o de carecer de este instrumento establece una frontera entre las personas. Uno de los principales objetivos de la escuela como institución es proporcionar a los niños el aprendizaje del lenguaje escrito. La tarea que la escuela tiene encomendada no es nada fácil puesto que debe competir con otros medios, tales como la televisión, los juegos de ordenador, a los cuales los niños y los jóvenes les dedican muchas horas, y, además ejercen una gran influencia sobre ellos. Como constatan muchos educadores una gran mayoría de adolescentes no sólo lee muy poco sino que además su nivel de lectura se limita al descifrado, con lo cual tienen mucha dificultad para comprender lo que leen, siendo éste uno de los problemas que más preocupan a los profesores de secundaria. La escuela debe por consiguiente, despertar el interés de los alumnos por la comunicación escrita, utilizando unos métodos de aprendizaje que tengan en cuenta las características de los aprendices, a saber, su desarrollo cognitivo y su madurez personal y afectiva, así como sus motivaciones de carácter más general. De todos es sabio, que el éxito y el fracaso escolar se fraguan, en gran medida, en relación con el aprendizaje de la lectura y de la escritura. Así pues, el aprendizaje formal de la lengua escrita constituye uno de los hitos de la enseñanza primaria. Este aprendizaje suele introducirse de forma temática alrededor de los 6 años, una edad en la que la mayoría de sujetos infantiles, como ya se ha comentado en los apartados anteriores, ha alcanzado un desarrollo considerable del lenguaje oral. Si bien en los comienzos del aprendizaje de la lengua escrita, la lectura y la escritura están íntimamente relacionadas, después adquieren una autonomía y se desarrollan como actividades diferenciadas. Así pues en este capítulo se procederá a examinar por separado cada uno de estos procesos, aparte de unas consideraciones generales de tipo pedagógico que engloban a la lectura y a la escritura. Se organiza de la siguiente manera, se aborda inicialmente el proceso de aprendizaje de la lectura, haciendo especial hincapié en los métodos y en las etapas de dicho aprendizaje; a continuación, se dedica un apartado bastante extenso a la adquisición de la lengua escrita, o sea la escritura, en el que se presentan en primer lugar, diferentes enfoques sobre las etapas que conducen a los niños a considerar los signos gráficos o las palabras escritas como representantes de la realidad. Se habla a continuación de las relaciones-diferencias y semejanzas entre el lenguaje oral y escrito, y finalmente se trata del aprendizaje de la producción escrita, con una revisión bastante exhaustiva de los temas que han estado y siguen estando en el candelero, como son entre otros la incidencia de la lengua escrita en el desarrollo cognitivo de los sujetos y la influencia de la variable edad en la construcción del texto narrativo.

Palabras claves: Neuro aprendizaje, Lenguaje escrito, Pedagogía, Lectura y Escritura. 


\section{SUMMARY}

Given the more technological nature of the activities that subjects must perform both in the workplace, with the increasingly widespread use of the computer, and at home, with the use of home appliances, whose operation requires careful reading of the instruction manual, it is noted that access and written language is necessary in Western societies. Probably, it is not an exaggeration to affirm that the mastery of written language is an indispensable means to access culture and knowledge in general. In fact, the fact of owning or lacking this instrument establishes a border between people. One of the main objectives of the school as an institution is to provide children with the learning of written language. The task that the school has entrusted is not easy because it must compete with other media, such as television, computer games, to which children and young people dedicate many hours, and also exert a great influence on they. As many educators note a large majority of adolescents not only read very little but also their reading level is limited to deciphering, which have a lot of difficulty to understand what they read, this being one of the problems that most concern teachers high school The school must therefore awaken students' interest in written communication, using learning methods that take into account the characteristics of the learners, namely, their cognitive development and their personal and affective maturity, as well as their motivations for learning. More general character. Of all it is wise, that the success and the scholastic failure are fraguan, to a great extent, in relation with the learning of the reading and the writing. Thus, formal learning of the written language is one of the milestones of primary education. This learning is usually introduced in a thematic way around the age of 6 , an age in which the majority of children's subjects, as already mentioned in the previous sections, have reached a considerable development of oral language. Although at the beginning of the learning of written language, reading and writing are closely related, then they acquire autonomy and develop as differentiated activities. So in this chapter we will proceed to examine each of these processes separately, apart from some general pedagogical considerations that encompass reading and writing. It is organized in the following way, initially the learning process of reading is approached, with special emphasis on the methods and stages of such learning; then, a quite extensive section is dedicated to the acquisition of the written language, that is to say the writing, in which are presented in the first place, different approaches on the stages that lead the children to consider the graphic signs or the written words as representatives of reality. The relationship-differences and similarities between oral and written language are discussed below, and finally it is about the learning of written production, with a fairly comprehensive review of the issues that have been and still are in the spotlight, as they are between others the incidence of the written language in the cognitive development of the subjects and the influence of the variable age in the construction of the narrative text.

Keywords: Neurolearning, Written language, Pedagogy, Reading and Writing. 


\section{INTRODUCCIÓN}

En lo que respecta al aprendizaje de la lectura los niños deben aprender las relaciones que existen entre los sonidos del habla, los sonidos que articulan mientras producen palabras, $y$ la representación gráfica de los mismos, letras o grafemas. Y aunque en la actualidad, muchos autores insisten en la dimensión cognitiva del proceso de la lectura, y en la importancia de buscar y reformular el significado del texto leído, no es menos cierto, que el proceso de descifrado, así como el de establecer correspondencias entre los grafemas y su traducción oral es básico en el aprendizaje de la lectura. (1)

Durante muchos años se ha considerado que abordar con garantías de éxito la lectura presuponía el dominio por parte del niño de una serie de requisitos que condicionaban el desarrollo ulterior. Estos requisitos solían salir a la luz pública a raíz de los fracasos acaecidos durante el aprendizaje de la lectura (una alteración en la estructuración témporo-espacial; una mala lateralización; el lenguaje oral insuficientemente desarrollado). Sin embargo, ninguna de las alteraciones mencionadas son específicas de la lectura, por cuya razón, este planteamiento ha sido cuestionado y puesto en entredicho los últimos años. Muchos autores suscriben en la actualidad la siguiente afirmación se aprende a leer leyendo, con lo cual se insiste en el carácter específico de la lectura. (2)

En los trabajos más recientes se considera que leer es básicamente buscar significado. La construcción de significado se lleva a cabo durante el proceso de la lectura, y, a la vez, se va reconstruyendo ya que es necesario acomodar nueva información. A lo largo de la lectura de un texto, así pues, el lector debe reevaluar y reconstruir el significado. Desde esta perspectiva, se puede afirmar que la lectura es un proceso dinámico y activo.

Goodman (2012) opina que aprender a leer empieza con el desarrollo del sentido de las funciones del lenguaje escrito. Abundando en lo que se ha dicho anteriormente, si leer presupone buscar significado, es necesario que el lector tenga un propósito para buscar significado en el texto. En conclusión, aprender a leer implica el desarrollo de estrategias para obtener significado del texto, así como el desarrollo de esquemas acerca de la información representada en el texto.

(1) Carretero, M. y Martín, E. 2010. (2) Solé, 2007. 


\section{DESARROLLO}

\section{Acerca de los métodos de lectura}

La escuela propone métodos distintos para abordar el aprendizaje de la lectura. Algunos hacen hincapié en la capacidad de entender el significado del texto a leer, o bien, en la capacidad de entender el significado del texto a leer, o bien, en la capacidad de descifrar o decodificar los signos gráficos o letras. El aprendizaje de la lectura, en este último caso, da prioridad a la correspondencia o asociación entre los sonidos o fonemas del lenguaje y a las letras que los representan.

Este método denominado, sintético, suele proceder de las unidades más pequeñas representadas por las letras o grafemas, a la combinación de dos o más letras -la sílaba, para pasar a continuación a la lectura de la palabra y finalmente de la frase. Considera primordial el proceso de descifrado frente al significado en la actividad lectora. El proceso que se propone al alumno es ir de la unidad más pequeña grafema - a la unidad de significada palabra y luego a la frase. Se trata, así pues, de un modelo ascendente (bottom-up).

Los métodos que insisten en el significado, denominados globales o analíticos, parten de la lectura de frases y animan a los alumnos a leerlas por el procedimiento del tanteo reconocimiento de la configuración de las palabras y su significado. Se introduce la lectura a partir de unidades de significado y, a continuación, se produce a analizar las palabras que integran la frase, para más adelante, descender a nivel de la sílaba y el grafema o letra. (2)

En este planteamiento el proceso es inverso al expuesto anteriormente, puesto que se pasa de la globalidad a la unidad, se trata así pues, de un proceso descendente (top-down).

El modelo ascendente da prioridad al proceso de identificación de los signos gráficos, las letras, y continúa luego con unidades lingüísticas más complejas palabras, oraciones y frases. La lectura según este modelo se inicia, así pues, con el análisis de los grafemas o letras (input gráfico), el descifrado gráfico (correspondencia sonido-grafema), y prosigue con el análisis sintáctico y la interpretación semántica, mediante la cual se procede a interpretar el significado del texto.

(2) Solé, 2007. 
En resumen, de todo el proceso mencionado, el descifrado, o sea la capacidad de hacer correspondencias entre el sonido y el grafema, se considera como un requisito indispensable para comprender el texto.

El modelo descendente prioriza, en cambio, la actividad del lector, en la medida que presupone que éste hace hipótesis sobre el significado del texto. El procesamiento del texto en los niveles inferiores (reconocimiento de palabras, descifrado) está sometido al control de los procesos inferenciales de nivel superior. Se considera que el lector tiene un conocimiento organizado del mundo, merced al cual discierno lo comprensible de lo incomprensible, y a la vez, le proporciona unas ideas sobre lo que es gramaticalmente plausible y lo que no es. La comprensión se convierte en el núcleo del proceso de lectura, y, por consiguiente, el descifrado pasa a ocupar un puesto secundario. (3)

El modelo interactivo hace hincapié en el lector y en el texto. Los procesos que intervienen en el procesamiento de la información textual descendente y ascendente son condiciones necesarias pero no suficientes para explicar la lectura. (4)

\section{Las etapas en la adquisición de la lectura}

Algunos autores han intentado establecer etapas o periodos en el proceso de adquisición de la lectura a partir de los presupuestos globales que inspiran sus hipótesis de trabajo.

Weiss (2018) considera que leer consiste básicamente en emitir hipótesis sobre un texto, por consiguiente, se trata de un proceso largo, jalonado por diferentes etapas.

Para este autor la primera fase se inicia entre los 2 y los 3 años de edad, en cuyo momento los niños entran en contacto con el mundo del lenguaje escrito, y se prolonga hasta los 6-7 años de edad. Los aprendizajes básicos se limitan al reconocimiento global de la configuración de algunas palabras escritas, como pueden ser el nombre de objetos o productos familiares. La transición a la etapa siguiente suele ser rápida, y depende, en gran medida, de la atención que el entorno haya prestado a las demandas infantiles.

Chall (2007) propone una serie de etapas en la adquisición de la lectura, y, sugiere que el primer estadio, denominado etapa 0 y, que va desde el nacimiento a los 6 años de edad, es con mucho el más importante por la cantidad de cambios que conlleva.

(3) Gove, 2009. (4) Smith, 2009. (4) Solé, 2007. 
Efectivamente, los niños que viven en un entorno cultural y social donde el lenguaje escrito tiene una presencia importante, tienen un conocimiento sobre el texto escrito, las palabras y las letras, lo que presupone, junto con las capacidades perceptivas y lingüísticas, una preparación excelente para abordar el aprendizaje de la lectura.

El descifrado, la primera fase del aprendizaje, presupone la capacidad de establecer la correspondencia pertinente entre los aspectos fónicos y gráficos. Los niños que acceden al descifrado dan un paso importante en el aprendizaje, puesto que adquieren autonomía y ya no es necesario que recurran al adulto para explorar el material escrito. Sin embargo, el aprendizaje de las características del código escrito, aun siendo una fase necesaria, no es suficiente para la adquisición de la lectura, puesto que la finalidad del niño no es descifrar los grafemas de una palabra, sino saber lo que la palabra quiere decir.

En el segundo estadio el lector gana en fluidez, aprende a utilizar la redundancia del lenguaje escrito y, en general, el contexto. La lectura, es cada vez más eficiente y rápida.

En el tercer estadio el lector lee para aprender. El conocimiento y el bagaje previos del lector desempeñan un papel importante. El lector debe obtener, ahora, información del texto escrito.

El cuarto estadio se caracteriza porque el aprendizaje se realiza mediante la lectura de libros y textos. El lector debe contrastar la información procedente de textos cuyos planteamientos son distintos, e, incluso contrapuestos. (5)

En el quinto estadio el lector aprende a leer en función de sus necesidades y propósitos. Se constata que los lectores eficientes son capaces de empezar un texto por el principio, el medio o el final. Ya tienen criterios para saber lo que deben leer y lo que no deben leer.

\section{La construcción de un sistema de signos gráficos: distintos enfoques}

La lengua escrita, como otros sistemas gráficos, constituye un conjunto de símbolos gráficos que mantiene unas relaciones arbitrarias y convencionales con la realidad que representa. Es precisamente, ese carácter arbitrario y convencional, lo que le distingue del dibujo, sistema de simbolización gráfica de tipo icónico, puesto que existe una relación de parecido entre los grafismos trazados sobre el papel y aquello que representan.

(5) Gove, 2009. 
En la actualidad muchos autores sostienen que la adquisición del lenguaje escrito es una creación eminentemente cultural, y, en las sociedades occidentales la institución escolar es la encargada de llevar a cabo dicho aprendizaje.

\section{El punto de vista interactivo y social}

El interés por la adquisición del lenguaje escrito y el valor simbólico de la escritura ha sido un tema estudiado desde diferentes puntos de vista. El más alejado en el tiempo, corresponde a los trabajos realizados por Vygotsky y Luria, hace algunos años ya, pero que han adquirido una gran vigencia en los últimos años, a consecuencia del impacto que estos planteamientos han tenido en los psicólogos norteamericanos, y en la divulgación posterior que ha dado a los mismos.

Vygotsky y Luria han intentado en numerosos estudios trazar la génesis, o utilizando la expresión que ellos acuñaron, la prehistoria del lenguaje escrito, es decir, el periodo preparatorio de la escritura.

Parafraseando sus escritos para que los niños den un significado a cualquier señal gráfica es preciso que entiendan que una marca visible, un dibujo, un pictograma, un signo gráfico, pueden representar o sustituir algo, lo cual equivale a transformar un estímulo-signo. Esta transformación debe ser consciente y deliberada. ¿Cómo se opera una transformación semejante?

Luria ideó un experimento interesante en el que pedía a niños de preescolar, de edades comprendidas entre los 3 y 5 años de edad, que recordasen unas frases complejas para su edad, al tiempo que se les entregaba un papel y un lápiz. Mediante esta técnica se pudo observar la evolución que seguían las producciones de los niños sobre el papel, y constatar en qué momento los trazos sobre el papel dejaba de ser simples garabatos para convertirse en símbolos destinados a recordar frases.

De esta manera se constató que entre los 3 y 4 años de edad las notas o trazos no tienen utilidad alguna puesto que los niños no los consultaban para recordar las frases. Sin embargo, algunos niños no seguían esta regla general, y aunque trazaban garabatos aparentemente indiferenciados, se observó, que consultaban los garabatos antes de reproducir las frases. 
Así, por ejemplo, una marca en una esquina significaba una vaca; en tanto que otra más arriba representaba un árbol. En estos casos, los trazos se convertían en símbolos mnemotécnicos puesto que desempeñaban un papel importante en el proceso de memorización.

Para Vygotsky el estadio mnemotécnico es el primer precursor de la escritura. Gradualmente, los niños transforman los trazos indiferenciados por pequeñas imágenes y dibujos que dan paso a los signos. De este modo se puede afirmar que, una primera fase los signos escritos son símbolos de primer orden ya que designan directamente objetos o acciones.

En una etapa posterior, los niños entienden que los signos escritos representen las palabras y acceden, por consiguiente a un simbolismo de segundo grado. De esta manera descubren que se pueden dibujar no sólo los objetos sino también las palabras.

Los símbolos escritos como símbolos de segundo grado, funcionan en tanto que designaciones de los símbolos verbales.

¿Cuál es el papel del lenguaje hablando en relación con el escrito? Si bien en sus inicios el lenguaje escrito cuenta con la ayuda o mediación del lenguaje hablado, éste, progresivamente, acaba por desaparecer como vínculo intermedio. En ese momento, el lenguaje escrito se convierte en un simbolismo directo que se percibe del mismo modo que el lenguaje hablado. 33

Desde una posición ideológicamente próxima a los planteamientos de Luria y Vygotsky, Lurçat (1963) afirma que los niños desde edades muy tempranas interpretan el acto gráfico como la representación o imagen de un objeto. Asimismo la escritura infantil es en un primer momento un complemento del dibujo, para después adquirir, progresivamente, una autonomía.

Lurçat hace hincapié en la importancia que se concede al aprendizaje de la escritura del propio nombre, ya que éste se considera como el eje central a partir del cual, el niño efectúa el paso del puro grafismo al dibujo de las letras de forma significativa.

En los comienzos, afirman Lurçat, coincidiendo con Vygotsky y Luria, el lenguaje oral acompaña la actividad gráfica, y a través de la convergencia de ambos, se va procediendo a la diferenciación entre imagen y signo. Esta diferenciación se ejerce tanto en la forma de los trazos como en su significación. 


\section{El punto de vista constructivista}

Desde la perspectiva el niño es un sujeto activo que categoriza, establece relaciones, construye hipótesis y busca regularidades. Es, en definitiva, un sujeto que reconstruye el lenguaje y lo hace a su modo.

En lo que respecta al aprendizaje de la escritura, los niños que viven en un medio urbano, antes del aprendizaje formal que se realiza en el marco escolar ya han desarrollado ciertas ideas acerca del lenguaje escrito.

Para Ferreiro (2009) la comprensión del sistema de escritura supone una actividad cognitiva de carácter más general. Para comprender cualquier sistema escrito el niño tiene que llevar a cabo un proceso activo de construcción de naturaleza cognitiva. Antes de llegar al reconocimiento del sistema alfabético, y a la relación entre el sonido el fonema de lenguaje oral y el grafema, la letra- de lengua escrita, los niños pasan por diferentes etapas.

Diversos trabajos efectuados con niños de edad preescolar de 4 a 6 años de edad para averiguar cómo interpretan las relaciones entre las formas escritas y la producción oral, ponen de manifiesto que los niños más pequeños consideran que el texto escrito no es una representación gráfica de la emisión hablada, sino que para ellos es un sistema de símbolos que mantiene una relación indirecta con el lenguaje hablado. A esa edad, consideran que para pasar del texto escrito a la emisión oral es preciso una reconstrucción del mismo.

Los niños suponen, además, que en el texto sólo se representan los elementos de la realidad que constituyen los referentes de la emisión. Así, sólo se representa el contenido referencial del mensaje pero no su forma verbal. Se produce un progreso cuando los niños asumen que el verbo también puede representarse por escrito, o más concretamente, cuando suponen que pueden representarse gráficamente no sólo los objetos o personas a las que se refiere la oración, sino también las relaciones entre ellas.

En un trabajo reciente Leal (2007) considera que en la construcción infantil de signos gráficos, se pueden hallar simbolizaciones a medio camino entre el dibujo y la escritura. Constata esta autora, mediante una investigación realizada con niños, de edades comprendidas entre los 4 a 6 años de edad que éstos disponen de una serie de ideas propias acerca de las palabras escritas, que ponen de manifiesto la presencia de rasgos icónicos, que no son propios de la lengua escrita convencional. Algunos ejemplos sacados de su trabajo son sumamente reveladores. A los 4 y 5 años de edad, los niños consideran que para escribir la palabra elefante 
se necesitan más letras o letras más grandes que para escribir hormiga, debido a la diferencia de tamaño entre ambos animales. En este tipo de argumentaciones se observa que los niños relacionan las diferencias de tamaño entre los referentes con la forma o medio para representarlo; o bien, afirman que la misma palabra escrita de forma distinta, por ejemplo, la palabra sopa, escrita en letra de imprenta y en letra cursiva, que ocupa más espacio, afecta la cantidad representada.

Los ejemplos expuestos manifiestan que en edades tempranas, los niños asimilan el código gráfico convencional a esquemas más próximos de un sistema icónico, como es el caso del dibujo o la imagen. Existe una tendencia a interpretar los signos gráficos, cuyo carácter arbitrario es evidente, como rasgos figurativos y simbólicos.

En fases posteriores del aprendizaje de la lengua escrita, los niños entenderán las relaciones que existen entre los sonidos del habla y los grafemas que los representan. Se trata, así pues, de un proceso activo de simbolización gráfica que conduce a un acontecimiento real del sistema alfabético en toda su complejidad, y no simplemente de la relación fonema-grafema.

\section{El aprendizaje de la producción escrita}

El aprendizaje de las formas gráficas o grafemas es sólo un aspecto de un proceso más general conocido como producción escrita. En la actualidad se considera que escribir es un proceso complejo que no se reduce a la capacidad de escribir palabras u oraciones sino que implica la capacidad de producir textos, es decir, un conjunto con una unidad temática integrado por frases que se relacionan entre sí.

Sin embargo, a lo largo de los años, los estudios que se han ocupado de estudiar el aprendizaje de la producción escrita desde una perspectiva evolutiva se han interesado por distintos aspectos. Unos se han ocupado de las relaciones -semejanzas diferencias- entre el lenguaje oral y el escrito, así como la incidencia de ambos en el desarrollo cognitivo; otros han comparado la sintaxis del lenguaje oral con la sintaxis del lenguaje escrito. Se han analizado asimismo las modificaciones producidas en el texto narrativo a tenor de la variable edad. Por otro lado, también se han tenido en cuenta la influencia de los factores socio-culturales en dicho aprendizaje. De todos estos elementos vamos a ocuparnos en las páginas que siguen. 


\section{Relaciones entre el lenguaje oral y el escrito}

Entre los aspectos más destacados que marcan las diferencias entre el lenguaje oral y el lenguaje escrito se destacan los siguientes:

\section{Contexto de producción}

El lenguaje oral depende más del contexto de la producción y tiene, por consiguiente, una relación más directa con la presencia de un hablante o productor del mensaje. El hecho de ser más dependiente del contexto, explica, a la vez el carácter más elíptico del lenguaje oral en lo que respecta a la estructura comunicativa del mismo.

En la medida que el lenguaje escrito depende menos del contexto extralingüístico tiene un carácter más descontextualizado, y por consiguiente, se produce un divorcio del discurso escrito en la relación con la dependencia perceptiva inmediata. Al tratarse de un lenguaje más descontextualizado resulta, a la vez, más objetivo, dado que el productor del discurso suele mantenerse alejado de la producción.

\section{Presencia o ausencia de un interlocutor}

Otro elemento diferenciador es la presencia de un interlocutor en la comunicación oral. Este hecho influye evidentemente en la organización o en las normas que rigen el discurso oral y el escrito. En cuanto a la norma escrita el locus psicológico de control se sitúa en el productor del texto, mientras que en el texto oral existe un control inter psicológico y compartido del tema del discurso por parte de los participantes implicados en la comunicación.

Por consiguiente, la producción del texto escrito exige estrategias planificadas de antemano y más elaboradas de las que exige el texto oral cuyo carácter es más espontáneo. El lenguaje escrito exige una organización consciente de los medios lingüísticos, una auto-reflexión lingüística que no es necesaria en el discurso oral. Parafraseando a Luria, que resume muy bien la incidencia del lenguaje escrito sobre el desarrollo cognitivo, el lenguaje escrito no sólo transmite información preparada sino que, además, procesa y clarifica nuestro pensamiento.

\section{La estructura: el diálogo y el monólogo}

Si bien se acepta que tanto el diálogo como el monólogo son dos formas apropiadas que se adecuan a las normas del lenguaje oral y escrito, es cierto que el diálogo suele darse más frecuentemente en el lenguaje oral, mientras que el monólogo es más propio del lenguaje escrito. 
La escuela, como ya se ha señalado antes, puede desempeñar un papel muy importante, durante el proceso de escolarización en lo que respecta a la transición de los escolares de un discurso basado especialmente en el diálogo, a una organización basada en el monólogo. Esto es así, por lo que respecta a la enseñanza del lenguaje escrito y a los ejercicios programados en otras áreas curriculares.

Asimismo, la escuela facilita que el lenguaje oral de los niños asuma las características del monólogo, de modo que el lenguaje sea cada vez más independiente del contexto, y por consiguiente más explícito. El momento crucial consiste, así pues, en pasar de las estrategias del discurso, basadas en cara a cara, y que son aptas para comunicarse en casa, a estrategias que exigen que se explicite cualquier conocimiento considerado como relevante, así como que se lexicalice o gramaticalice toda la información. Estos aspectos que se acaban de mencionar, en el discurso oral son asumidos por otros canales no lexicales, tales como la prosodia, la entonación y otros indicadores no verbales.

En resumen, el monólogo es una formación compleja con unas exigencias cognitivas más explícitas de las que exige el diálogo, y con un mayor grado de autorreflexión.

Para que se dé el paso del oral al escrito los niños deben adquirir unas estrategias del discurso nuevas que le permitan diferenciar la información nueva de la vieja, introducir enlaces de cohesión, así como la perspectiva desde y a través del tema.

\section{Estudios comparativos sobre la sintaxis del lenguaje oral y escrito}

La mayoría de estos estudios analizan el desarrollo del lenguaje escrito durante un período de tiempo determinado, o bien comparan el desarrollo del lenguaje oral y escrito en niños de distintas edades o de distintos niveles de escolaridad.

El material que sirve de base al estudio consiste en comparar la producción de historias narrativas orales y escritas. La unidad de análisis es la frase y, el estudio se centra, concretamente, en la sintaxis. Las variables que se tienen en cuenta son, la longitud y la complejidad de las frases orales y escritas, el porcentaje de las distintas frases producidas, así como el porcentaje de los tipos de oraciones subordinadas producidas en las diferentes formas de lenguaje, el oral y el escrito. 
Habida cuenta que ese tipo de pruebas requieren cierto manejo del lenguaje escrito, la población estudiada suele estar integrada por niños que cursan grados intermedios y altos de la enseñanza primaria y de la secundaria, de 9 a 15 años de edad.

Los resultados obtenidos demuestran que las producciones escritas suelen contar con frases más complejas y con un número mayor de subordinadas que las producciones orales. Las diferencias son significativas en lo que respecta a la longitud, la complejidad de la frase y la subordinación.

En conclusión, a pesar de que las narraciones orales son más largas que las escritas en todos los grupos de edad estudiados, los niños producen un número significativamente mayor de oraciones subordinadas en las narraciones escritas, especialmente, a partir de los 9; 5 años de edad.

\section{Cambios durante la escolaridad entre el lenguaje oral y el lenguaje escrito}

Si bien a los 6 años de edad, cuando los niños empiezan la escuela primaria tienen una competencia lingüística a nivel oral lo suficiente desarrollada que les permite producir distintas formas del discurso oral, los esquemas del lenguaje escrito todavía están poco evolucionados.

Por consiguiente, las habilidades comunicativas orales y escritas a los 6 años de edad están desigualmente desarrolladas.

Sin embargo, entre los 8 y los 11 años de edad, se observa un cambio importante. Efectivamente, a esas edades los niños dominan los aspectos esenciales de la escritura y disminuyen las diferencias entre las narraciones orales y escritas.

A lo largo de la escolaridad se observa un interés creciente por el proceso de la escritura, lo que redunda positivamente en el propio lenguaje escrito. Efectivamente, en la medida que los sujetos infantiles se fijan más en el texto escrito, desarrollan la capacidad de examinar, modificar y, finalmente, producir un texto que refleje con mayor exactitud y precisión el significado.

A los 12 años de edad, cuando los niños inician el estudio de la operatividad formal, se produce otro cambio importante, el lenguaje escrito empieza a adquirir una superioridad en cuanto a su estructura en relación con los textos orales. A la larga esta superioridad se afianzará. 
Por todo ello, Bruner y Olson, consideran que el aprendizaje del texto y del lenguaje escrito influyen directamente en el desarrollo cognitivo, puesto que el lenguaje escrito permite una reflexión consciente de las estructuras implícitas en la lengua materna.

Una reflexión consciente de esta naturaleza constituye, prosiguen los mismos autores, un mecanismo potente para conectar y relacionar los dominios de la actividad simbólica del lenguaje con las estructuras generales de lo cognitivo.

Según Vygotsky, cuando un individuo domina el lenguaje escrito, el sistema subyacente a la naturaleza de los procesos mentales experimenta un cambio fundamental dado que cuenta con un sistema de símbolos externos que median en la organización de todas las operaciones intelectuales básicas.

\section{Las modificaciones en el texto narrativo como consecuencia de la variable edad}

Una narración se presenta como una secuencia de proposiciones concatenadas, cada una de las cuales remite a un evento o estado. Por lo general, el orden de las proposiciones sigue, regularmente, el orden cronológico de los eventos.

Los textos narrativos escritos presentan una serie de indicadores lingüísticos que les dan cohesión interna, y que constituyen las marcas superficiales de la organización del texto. Las marcas de enumeración son los pronombres, las formas verbales y los términos de localización espacio-temporales. También se tiene en cuenta la utilización de un léxico adecuado, o sea que las palabras utilizadas pertenezcan a campos semánticos afines, y que mantengan entre sí las relaciones de jerarquización pertinentes.

La capacidad que tienen los niños para producir textos narrativos escritos cambia con la edad. El estudio de la utilización que hacen los niños de distintas edades de los indicadores lingüísticos antes mencionados constituye un dato importante de los cambios producidos durante el proceso evolutivo.

Algunos trabajos que han estudiado la evolución del texto narrativo 36 señalan que se produce una descentración o distanciamiento del productor o narrador en relación al texto elaborado. Este distanciamiento se traduce en los cambios observados en la narración. Se produce, así pues, el paso de un sistema de referencia personal, caracterizado por la presencia casi exclusiva del narrador en los hechos relatados, a otro sistema, en el cual la experiencia se 
reconstruye teniendo en cuenta situaciones cada vez más variadas, así como por la presencia de interlocutores diferentes.

Por lo que respecta a la utilización de los pronombres, en relación con la edad, de los 6 a los 7 años de edad, se observa un predominio casi absoluto del pronombre <<yo >>. Este hecho indica que existe una identificación entre el narrador y el protagonista del evento que se narra. Hacia los 8 o 9 años de edad el narrador empieza a perder protagonismo y aparecen otros protagonistas en los eventos narrados.

En lo que respecta a las marcas de localización temporales, se observan asimismo, cambios con la edad. Los niños más pequeños del grupo, 6-7 años de edad no suelen especificar en qué momento se sitúa el evento que relatan (ej. <<Fui a pescar, fui al campo>>). En el grupo de edad superior, 7-8 años, suelen aparecer indicadores temporales fuertes, en el sentido que el narrador establece una relación fuerte entre el momento que se produce el evento y el momento de la narración del mismo (ej. <<Ayer >>, <<mañana >>, <<el jueves por la mañana >>). A partir de los 8 años de edad, la relación con el evento narrado se debilita, parece como si el narrador adoptase un distanciamiento en relación con los eventos.

En cuanto a la utilización de las formas verbales, se observa que los niños pasan por diferentes fases. En las edades inferiores, 6-7 años, el predominio del pretérito perfecto, (he ido al cine, he ido a la escuela) denota una identificación del narrador con las acciones narradas, y una proximidad temporal muy grande en relación con el momento en el que se efectúa la narración. Progresivamente, las formas de pasado, como el pretérito indefinido, aparecen con mayor frecuencia, con lo cual los acontecimientos relatados se sitúan en un pasado distante en relación con el momento de la enunciación. Finalmente, a los 8-9 años de edad, hacen acto de presencia los tiempos de <<origen ficticio >>. Con la introducción del presente, los sujetos narran eventos pasados como si se tratara de un evento actual.

Así pues, los niños pasan de una centración relacionada con el <<ahora〉> y el <<aquíi> en que se produce la emisión del relato a una descentración creciente del momento de la enunciación.

\section{La influencia de los factores socio-culturales en el aprendizaje de la lengua escrita}


Otro tipo de trabajos tienen en cuenta cuáles son los factores socio-culturales que facilitan la adquisición del lenguaje escrito. Insisten, además, en la necesidad de tener en cuenta, de forma crítica, las variables socio-culturales al estudiar la adquisición del lenguaje escrito. En todos estos trabajos se reconoce la importancia que tiene el grado de organización del discurso y del texto. Además se hacen algunos estudios sobre las diferencias sistemáticas que se dan entre la organización socio-cultural del lenguaje oral y escrito. En realidad, se pone más el acento en las variables socio-culturales del lenguaje oral y escrito.

Entre los aspectos estudiados destacan, los usos funcionales del lenguaje escrito, la organización diferencial de los distintos entornos comunicativos, representado por el hogar y la escuela. Las propuestas que realizan este tipo de trabajos son de tipo global e insisten en la conveniencia de tener en cuenta, simultáneamente, los aspectos lingüísticos, funcionales y socio-culturales. 


\section{CONCLUSIÓN}

Uno de los temas que surgen en torno al aprendizaje del lenguaje escrito de una forma casi invariable a lo largo de los años se refiere a la edad o al memento más adecuado e idóneo para que el niño entre en contacto con el lenguaje escrito. La respuesta no es fácil, puesto que existe más de una alternativa.

Sin embargo, en los últimos años se ha hecho hincapié en la conveniencia de que el contacto que establezca el niño con el lenguaje escrito sea algo natural. En realidad, la gran mayoría de niños que viven en una sociedad perteneciente al mundo occidental desde muy pequeños, ya están en contacto con el lenguaje escrito. Los productos que forman parte de su entorno habitual, tales como las botellas, los botes de productos alimenticios, los yogurts que comen llevan etiquetas con el nombre escrito del producto. En ese sentido los niños saben ya que los signos gráficos, lo que está escrito tiene un significado.

Una vez constatado este hecho, es aconsejable que la escuela introduzca el lenguaje escrito a partir de aquellas palabras que tengan un alto valor significativo para el niño, tales como su nombre propio, y el nombre de los objetos más usuales. En sus orígenes la escritura, como ya se ha se ha señalado mantiene vínculos muy estrechos con el dibujo.

Habida cuenta que los niños deben enfrentarse con el aprendizaje de un sistema de signos gráficos arbitrarios, un sistema alfabético por lo que respecta al aprendizaje del castellano y del catalán, en el cual los grafemas o letras representan a los sonidos del habla es importante promover las operaciones de análisis y de síntesis. Se considera asimismo oportuno que se dé una correlación entre lo que se lee y lo que se escribe.

La lectura se basa, principalmente, en el análisis auditivo y visual de los signos gráficos. Por consiguiente, es sumamente importante, que los niños aprendan a identificar los sonidos de la lengua y a analizar los signos de la lengua escrita.

Asimismo, la escuela puede facilitar el aprendizaje del lenguaje escrito, mediante la potenciación del relato y la narración en el lenguaje oral.

Como ya hemos señalado anteriormente, el lenguaje escrito tanto en su estructura como en su organización suele adoptar las formas de la narración, el relato y la descripción.

Por lo tanto, la escuela puede proporcionar estos instrumentos lingüísticos a los niños que carecen de ellos mediante la lectura de cuentos y de historias, la explicación oral de 
experiencias o vivencias personales que se han producido en el pasado. La maestra o el maestro pueden y deben ayudar a los niños a organizar su relato oral, a darle una coherencia interna, mediante el aprendizaje de las técnicas que presiden la construcción del texto escrito.

Es sumamente interesante que los niños descubran la relación entre el significado y la representación gráfica mediante actividades que incluyan la lectura y la escritura y que tengan una finalidad y un sentido en sí mismas.

La lectura y la escritura aparecen como actividades relacionadas entre sí, de modo que los niños con unos conocimientos suficientes sobre las fundaciones del lenguaje escrito ya están en condiciones de empezar a escribir. Asimismo, es válida la afirmación según la cual, para escribir, es necesario aprender a leer. 


\section{REFERENCIAS}

AJURIAGUERRA, J. DE, GUINARD, F., JAEGGI, A. KOCHER, F., MAQUARD, M., PAUNIER, A., QUINODOZ Y SIOTIS, E. (2001) Ed. Cast. <<Organización psicológica y perturbaciones del desarrollo del lenguaje»>, en PIAGET, J., Y OTROS, Introducción a la Psicolingüística. Buenos Aires Proteo, p.p. 129-161. 1969.

ANGUERA, M.T. (2010) Manual de Prácticas de Observación. México. Trillas.

ANTON, M. (2010) Psicomotricidad en el parvulario. Barcelona. Laia.

BALTES, P. B., REESE, H.W. y NESSELROADE, J.R. (2010) Métodos de investigación en psicología evolutiva: Enfoque del ciclo vital. Madrid: Ediciones Morata.

BOADA, H. (2010) <<Comunicación y bilingüismo〉>. En M. Siguan (Coor). Estudios de psicolingüística. Madrid: Pirámide.

BOADA, H. (2012). El desarrollo de la comunicación en el niño. Barcelona: Anthropos.

BRONCKART, J. P. (2011) <<Procesos y estructuras del desarrollo del lenguaje>>. Monografía de Infancia y Aprendizaje. La adquisición del lenguaje, 85-104.

CARRetero, M. y GARCIA MAdRUGA, J.A. (2012) Lecturas de Psicología del Pensamiento. Madrid. Alianza Psicología.

CAZDEN, C.B. (2012) <<La lengua escrita en contextos escolares>> en FERREIRO, E. Y GOMEZ PALACIO, M. Comp. Nuevas perspectivas sobre los procesos de lectura y escritura. Madrid. Siglo veintiuno.

COOPERSMITH, S. (2011) <<Estudios sobre la propia estima〉>. Psicología Contemporánea. Selección del Scientific American 393-400.

DELVAL, J. (2008) Lecturas de Psicología del Niño. 2 Vol. Madrid. Alianza Editorial. 
FERREIRO, E. y GOMEZ PALACIO, M. (2012) Nuevas perspectivas sobre los procesos de lectura y escritura. México: Siglo XXI. Editores, 13-28.

FREUD, S. Obras completas p.p. 1097-1123. Madrid. Ed. Biblioteca. Nueve. (2012).

GARVEY, C (2011) El habla infantil, Madrid: Ediciones Morata.

INSTITUTO DE CIENCIAS DE LA EDUCACIÓN DE LA UNIVERSIDAD AUTONOMA DE BARCELONA (1999) Mujer y Educación. El sexismo en la enseñanza. Barcelona. Universidad Autónoma.

MARTINEZ ARIAS, M.R. (2012) <<Métodos de Investigación en Psicología Evolutiva»> en MARCHESI, A., CARRETERO, M. y PALACIOS, J. Comp.Psicología Evolutiva Vol. 1. Madrid. Alianza Editorial.

MORENO, M. y COL. (2010) Ciencias Aprendizaje y Comunicación. Barcelona. Laia.

PIAGET, J. (2012) La répresentation du monde chez l’enfant. París. P.U.F. Ed. Cast. La presentación del mundo en el niño. Madrid, Morata, 1973.

PIAGET, J. (2011) Le jugement moral chez l’enfantl París Alcan. Ed. Cast. El criterio moral en el niño. Barcelona. Fontanella. 1971.

PIAGET, J. (2012) La Naissance de l'intellicence chez l'enfant Neuchâtel y París: Delachaux Niestlé. Ed. Cast. El nacimiento de la inteligencia en el niño. Madrid. Aguilar. 1969.

PIAGET, J. (2010) <<Les Mecanismes Perceptifs>> en FRAISSE, P. y PIAGET, J. Traité de Psychologie Expérimentale. Vol. 1-9. Ed. Cast. En PIAGET, J. y FRAISSE, P. Tratado de Psicología Experimental. Vol. 1-9. Buenos Aires. Paidos. 1972/74.

PIAGET, J. e INHELDER, B. (2011) La psychologie de l'enfant. París: Presses Universitaires de France. Ed. Castellana. La psicología del niño. Barcelona, Ariel, 1977.

SIGUAN, M. (2010) Lenguaje y clase social en la infancia. Madrid: Pablo del Río Editor. 
VYGOTSKY, L.S. (2000) <<Aprendizaje y desarrollo intelectual en la edad escolar»>. En A.R. Luria, A.N. Leontiev, L.S. Vygotsky. Psicología y pedagogía. Madrid: Akal, 23-39. 